\title{
Pandemia de COVID-19 e violência doméstica na conjuntura sociopolítica brasileira
}

\author{
Maria Carmen Aires Gomes' (iD 0000-0001-7402-4353 \\ Alexandra Bittencourt de Carvalho ${ }^{2}$ (i) 0000-0003-3159-2021 \\ 'Universidade Federal de Viçosa, Viçosa, MG, Brasil. 36570-000 \\ 2Universidade Federal de Minas Gerais, Belo Horizonte, MG, Brasil. 31270-901
}

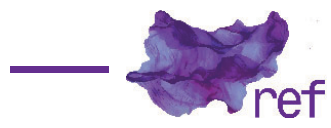

\begin{abstract}
Resumo: Em tempos de pandemia de COVID-19, o isolamento social torna-se medida importante para determos o novo coronavírus que assola o mundo. Ao mesmo tempo, tal medida esbarra em uma realidade: a violência contra as mulheres que, em sua maioria, ocorre dentro de casa. 0 objetivo do artigo é promover uma análise discursivo-crítica da conjuntura brasileira que atravessa a violência doméstica em tempos de pandemia, relacionando-a às respostas do governo brasileiro e do Ministério da Mulher, da Família e dos Direitos Humanos para combatê-la. A análise revela que tais respostas estão calcadas em um viés ideológico sustentado, principalmente, pela noção de família nuclear e pela negação do gênero, o que dificulta não só as ações concretas e eficazes para coibir a violência, como também desconsidera as intersecções de raça, classe e gênero, fundamentais para a produção de políticas públicas.
\end{abstract}

Palavras-chave: violência doméstica; COVID-19; interseccionalidades; análise de discurso crítica.

\section{COVID-19 pandemic and domestic violence in the Brazilian socio-political context}

Abstract: In times of the COVID-19 pandemic, social isolation becomes an important measure to stop the new virus that is plaguing the world. At the same time, this measure comes up against a reality: violence against women, which mostly occurs at home. The objective of this article is, then, to promote a discursive-critical analysis of the Brazilian conjuncture that goes through domestic violence in times of pandemic, relating it to the responses of the Brazilian government and the Ministry of Women, Family and Human Rights to combat it. over there. The analysis reveals that such responses are based on an ideological bias sustained, mainly, by the nuclear notion of the family and by the negation of gender, which hinders not only concrete and effective actions to curb violence, but also disregards the intersections of race, class and fundamental to the production of public policies.

Keywords: Domestic violence; COVID-19; Intersectionality; Critical Discourse Analysis.

La pandemia de COVID-19 y la violencia doméstica en la situación sociopolítica brasileña Resumén: En tiempos de la pandemia de COVID-19, el aislamiento social se convierte en una medida importante para detener el nuevo coronavirus que asola el mundo. Al mismo tiempo, tal medida se enfrenta a una realidad: la violencia contra las mujeres, que en su mayoría tiene lugar dentro del hogar. El objetivo del artículo es promover un análisis discursivo y crítico de la situación brasileña que atraviesa la violencia doméstica en tiempos de pandemia, relacionándola con las respuestas del gobierno brasileño y del Ministerio de la Mujer, la Familia y los Derechos Humanos para combatirla. El análisis revela que esas respuestas se basan en un sesgo ideológico sostenido principalmente por la noción de familia nuclear y la negación del género, que no sólo obstaculiza las acciones concretas y eficaces para frenar la violencia, sino que también pasa por alto las intersecciones de raza, clase y género fundamentales para la producción de políticas públicas.

Palavras clave: Violencia contra las mujeres; COVID-19; Interseccionalidad; Análisis crítico del discurso. 


\section{Introdução}

O objetivo deste artigo é fazer uma análise discursivo-crítica da conjuntura sociopolítica e cultural sobre a relação entre a pandemia de COVID-19 e a violência doméstica no contexto brasileiro de forma a entender como o governo brasileiro e o Ministério da Mulher, da Família e dos Direitos Humanos (MMFDH) reagiram a esse problema por meio de propostas de ações e estratégias de enfrentamento.

Dentro do viés realista-crítico metodológico proposto por Lilie Chouliaraki e Norman Fairclough (1999) para se analisar como discursos funcionam ideologicamente em redes de práticas sociais, a análise de conjuntura é o ponto de partida para compreendermos quanto complexas são as práticas sociais em que o discurso se constitui como um de seus elementos em interconexão com outros, quais sejam: atividade material, fenômeno mental e relações sociais. O referido método discursivo-crítico envolve cinco estágios: (1) ênfase em um problema social que tenha um aspecto semiótico, (2) inserção do problema em uma análise de conjuntura, de forma a (3) identificar obstáculos para que esse problema seja resolvido, (4) a escolha da rede de práticas sociais na qual o problema se insere, para enfim (5) analisar como os discursos se constituem e são constituídos, por meio da análise linguístico-textual (Norman FAIRCLOUGH; Iran Ferreira de MELO, 2012; Maria Carmen Aires GOMES; Viviane VIEIRA, 2020). Após a análise linguístico-textual, compreender como o problema está funcionando na rede de práticas sociais, identificando maneiras possíveis de superar os obstáculos para que sejam solucionados.

Dessa forma, o problema social a ser estudado neste artigo é a violência doméstica contra as mulheres no contexto de pandemia de COVID-19, considerando as conjunturas local e mundial em que ele se constitui à luz dos acontecimentos, cenários, atores, relações de forças e articulação (relação) entre estrutura e conjuntura historicamente situadas. O objetivo, a partir da análise de conjuntura por um viés discursivo-crítico, é identificar não só os principais acontecimentos em um determinado momento, as forças discursivo-políticas em conflito, a articulação e a desarticulação das lutas hegemônicas, mas também como as relações de poder "podem ser de confronto, de coexistência, de cooperação e estarão sempre revelando uma relação de força, de domínio, igualdade ou subordinação" (Betinho Herbert José de SOUZA, 1997, p. 12).

Para este estudo, foram escolhidos textos produzidos por agentes e instituições legitimados local e mundialmente que atuam e produzem discursos sobre a problemática, quais sejam: Organização Mundial da Saúde (OMS), Organização das Nações Unidas (ONU), Fórum Nacional de Segurança Pública (FNSP), Instituto de Pesquisa Econômica Aplicada (IPEA) e o Ministério da Mulher, da Família e dos Direitos Humanos (MMFDH). O objetivo é observar, por meio da análise de conjuntura, através de textos, que práticas estão em jogo, como os agentes participam desta situação e como controlam e exercem seus poderes, a partir da declaração oficial de que o mundo estava vivendo uma pandemia. O ponto de partida da análise foi a divulgação e circulação na sociedade brasileira do relatório produzido pelo Fórum Nacional de Segurança Pública sobre os impactos da pandemia no aumento de casos de violência doméstica. O recorte cronológico da seleção dos textos envolve, portanto, os meses de março e abril, para compreendermos como o problema social em análise se constituía e era constituído discursivamente nesta rede de práticas sociais: saúde, política, econômica e social.

\section{Conjuntura Socio-histórica: relaçōes de poder e forças}

O problema sociossemiótico em análise tem início em 06 de abril de 2020, após a OMS declarar oficialmente que o mundo estava vivendo uma pandemia de COVID-19. O secretáriogeral da ONU, António Guterres, chama atenção, pela primeira vez, para o "chocante aumento global da violência doméstica" (ONU, 2020). Segundo ele, decorrente do "aumento das pressões econômicas e sociais e do medo" (ONU, 2020), e, em tom de preocupação, adverte que "a prevenção e a reparação nos casos de violência contra as mulheres sejam uma parte vital de seus planos nacionais de resposta contra a COVID-19" (ONU, 2020). Não é difícil de imaginar que essa situação poderia ocorrer, já que o isolamento social, considerado uma das medidas de maior segurança contra a contaminação, sujeitaria mulheres a todo tipo de violência dentro das próprias casas.

António Guterres exige que os governos implementem "sistemas de alerta de emergência em farmácias e supermercados" (ONU, 2020), pois, naquele momento (06 de abril), eram os únicos estabelecimentos comerciais que permaneciam abertos em muitos lugares. Vários países receberam esse alerta da ONU, mas muitos já se deparavam com tal situação, visto que instrumentos antes utilizados para detectar as múltiplas violências contra as mulheres estavam sendo pouco usados, como por exemplo o registro de Boletim de Ocorrência (BO), denúncia física nas delegacias e nos postos de atendimentos. Segundo Guterres, vários países notaram que o número de chamadas para as linhas de ajuda dobrou, principalmente "em comparação com o mesmo mês de 2019" (ONU, 2020). 
A ONU recomenda e elenca uma série de ações que os países ao redor do mundo podem realizar de forma a não deixar mulheres mais vulneráveis do que já estão em contexto de isolamento e distanciamento social:

aumentar o investimento em serviços online e em organizações da sociedade civil; garantir que os sistemas judiciais continuem processando os agressores; estabelecer sistemas de alerta de emergência em farmácias e mercados. Também recomenda declarar abrigos para vítimas de violência de gênero como serviços essenciais; criar maneiras seguras para as mulheres procurarem apoio, sem alertar seus agressores; evitar libertar prisioneiros condenados por violência contra mulheres; ampliar campanhas de conscientização pública, principalmente as voltadas para homens e meninos. (ONU, 2020).

Em 08 de abril, também no site da ONU, Phumzile Mlambo-Ngcuka (2020) circula um texto em que chama atenção para o aumento de casos de violência em vários continentes e destaca que:

Em Argentina, Canadá, França, Alemanha, Espanha, Reino Unido e Estados Unidos, autoridades governamentais, ativistas dos direitos das mulheres e parcerias da sociedade civil denunciaram crescentes denúncias de violência doméstica durante a crise e aumento da demanda por abrigos de emergência. As linhas de apoio em Singapura e Chipre registraram um aumento de chamadas em mais de $30 \%$. Na Austrália, $40 \%$ de trabalhadores e trabalhadoras da linha de frente em uma pesquisa de New South Wales relataram um aumento de pedidos de ajuda, porque a violência está aumentando em intensidade. (MLAMBO-NGCUKA, 2020).

Os efeitos e impactos provenientes da pandemia de COVID-19 mostram-nos que as ações não podem ser gerenciadas em apenas níveis local, regional, nacional, mas precisa-se considerar a estrutura global. Ainda que cada cultura, cada país e cada continente tenham suas especificidades sociais e políticas, a violência contra as mulheres é compreendida como uma das maiores violações dos direitos humanos. Sobre isso, Mlambo-Ngcuka (2020) adverte ainda que: "Nos 12 meses anteriores, 243 milhões de mulheres e meninas (de 15 a 49 anos) em todo o mundo foram submetidas à violência sexual ou física por um parceiro íntimo.".

O Brasil, infelizmente, não difere muito dessa situação e se encontra dentro dessas estatísticas. No Atlas da Violência 19, publicado pelo IPEA em parceria com o Fórum Brasileiro de Segurança Pública (FBSP), no que tange à violência contra mulheres, verificou-se o "crescimento expressivo de $30,7 \%$ no número de homicídios de mulheres no país durante a década em análise (2007-2017), assim como no último ano da série, que registrou aumento de 6,3\% em relação ao anterior" (IPEA; FBSP, 2019, p. 35).

O estudo ainda ressalta que a violência se torna mais bruta e cruel quando interseccionada pelo eixo da racialidade: "Em números absolutos a diferença (entre mulheres negras e não negras) é ainda mais brutal, já que entre não negras o crescimento é de 1,7\% e entre mulheres negras de 60,5\%" (IPEA; FBSP, 2019, p. 35). Esse dado leva-nos a acreditar que as políticas públicas devem ser elaboradas através de um viés interseccional (Kimberlé W. CRENSHAW, 2004), ou seja, tais políticas devem ser diferenciadas e múltiplas levando em consideração os eixos identitários que colidem no gênero. Ainda que os dados não apontem diretamente para uma intersecção classe-raça-gênero-saúde, não podemos deixar de presumir que esse tipo de violência se realiza e se executa nessa colisão identitária.

O Atlas da Violência 19 chama atenção para o fato de que "a significativa maioria das mortes violentas intencionais que ocorrem dentro das residências são perpetradas por conhecidos ou íntimos das vítimas" (IPEA; FBSP, 2019, p. 39). O documento adverte: "ainda que o número real de feminicídios não seja igual ao número de mulheres mortas dentro das residências, tal proxy pode servir para evidenciar a evolução nas taxas de feminicídio no país" (IPEA; FBSP, 2019, p. 40). Considerando o local de ocorrência da violência, o documento do Atlas verificou que "do total de homicídios contra mulheres, $28,5 \%$ ocorrem dentro da residência (39,3\% se não considerarmos os óbitos em que o local do incidente era ignorado)" (IPEA; FBSP, 2019 , p. 40). Esses dados mostram-nos que a violência doméstica deixa de ser um problema da esfera privada e se torna um problema estrutural, institucional e democrático.

Em fevereiro de 2019, o FBSP, em parceria com o Instituto Datafolha, realizou a pesquisa Visível e Invisível: a vitimização de mulheres no Brasil, concluindo que apenas 10,3\% das mulheres que afirmaram ter sofrido algum tipo de violência no período de 12 meses entre 2018 e 2019 procuraram uma delegacia da mulher, $8 \%$ procuraram uma delegacia de polícia comum e 5\% das respondentes ligaram para o 190 (FBSP; INSTITUTO DATAFOLHA, 2019). Os resultados mostram-nos ainda que quando 'questionadas sobre o local onde sofreram a violência': $42 \%$ disseram em casa/residência, $29 \%$ na rua, $8 \%$ na internet e $8 \%$ no trabalho. Quanto à relação com o agressor, a pesquisa aponta que $76,4 \%$ das mulheres que sofreram violência afirmam que o agressor era alguém conhecido: $23,8 \%$ por cônjuge, companheiro ou namorado; $21,1 \%$ por vizinho e $15,2 \%$ por ex-cônjuge, ex-companheiro e ex-namorado. Ao serem questionadas sobre o que fizeram depois de sofrer violência: $10,3 \%$ procuraram a delegacia de mulheres, $8 \%$ 
procuraram a delegacia comum, 5,5\% ligaram para o 190, 15\% pediram ajuda aos familiares e, lamentavelmente, 52\% não fizeram nada; aqui o estudo ressalta que em 2016 obteve o mesmo resultado. Essa pesquisa nos mostra o quanto as mulheres brasileiras são alvos todos os dias de agressores violentos dentro de suas próprias casas. Essa violência não é escondida, camuflada; a vizinhança tudo observa, sente e, às vezes, age: $28 \%$ viram já mulheres que residem na sua vizinhança serem agredidas por pessoas com quem tem relação de parentesco ou proximidade.

A ONU ressalta que as "mulheres não somente enfrentam entraves quanto ao acesso a serviços essenciais ou ordens de proteção, mas que 'o impacto econômico da pandemia pode criar barreiras adicionais para deixar um parceiro violento'” (Letícia BOND, 2020). Pâmela Rocha Vieira, Leila Posenato Garcia e Ethel Leonor Noia Maciel (2020, p. 03) chamam atenção para o fato de que "a presença dos homens em casa não significa cooperação ou distribuição mais harmônica das tarefas entre toda a família, mas sim o aumento do trabalho invisível e não remunerado das mulheres", trazendo à tona as relações patriarcais, que "implicam desvantagens para as mulheres e permitem aos homens dispor do corpo, do tempo, da energia do trabalho e da energia criativa destas" (Flávia BIROLI, 2018, p. 11).

Embora essas violências ocorram nos espaços privados e domésticos, elas reverberam e se tornam um problema da nossa democracia. Confluindo com as relações patriarcais, estão a racialidade, a classe, a faixa etária e a localização geográfica, isto é, o patriarcado não é o único sistema de opressão que atinge as mulheres. Esse problema se torna ainda mais complexo se considerarmos a metodologia negra feminista interseccional para o problema da violência doméstica contra mulheres: mulheres indígenas, quilombolas, encarceradas, em situação de rua, mulheres trans, travestis, prostitutas, lésbicas, negras, periféricas, rurais... nem todas são afetadas pelo mesmo tipo de violência; portanto, reiteramos que não se pode pensar nas mesmas ações de enfrentamento para todas elas. Conforme Maria Cecília MacDowell dos Santos (2017), essas intersecções "produzem situações diferenciadas de violência doméstica, bem como recursos e acessos desiguais ao reconhecimento e ao exercício de direitos" (SANTOS, 2017, p. 51).

Em uma conversa on-line com pesquisadores brasileiros sobre feminicídio, genocídio e pandemia, no dia 04 de junho de 2020, Ângela Davis afirma que tão pandêmico como o COVID-19 também é a violência contra as mulheres e o racismo. Para entender a violência doméstica contra mulheres no contexto brasileiro, é preciso descolonizar, despatriarcalizar, descisheteronormatizar e transformar a maneira de se pensar o modo capitalista de produção neoliberal.

Para compreender a problemática sociossemiótica da violência doméstica é preciso considerar tanto as fontes não acadêmicas como as fontes acadêmicas para que tenhamos uma visão ampla da ordem social. Em relação à conjuntura acadêmica, a violência contra as mulheres tem sido amplamente discutida. Se colocarmos o descritor 'violência doméstica' na plataforma Scielo, são apresentados 1076 artigos produzidos em periódicos. Esses estudos apontam para muitas das questões problematizadas pelos institutos de pesquisa e organizações de direitos humanos, como veremos adiante.

Embora as mulheres chefiem 28,9 milhões de famílias, não estão seguras e protegidas pelo Estado. A violência de gênero que vivenciamos hoje, principalmente em nosso contexto brasileiro, reflete, e muito, as dinâmicas contraditórias das relações entre família, trabalho e vida pessoal, como se todo o ônus do cuidado fosse da mulher (Cinzia ARRUZZA; Tithi BHATTACHARYA; Nancy FRASER, 2019). Heloisa Bianquini (2020), discutindo sobre o combate à violência doméstica em tempos de pandemia e o papel do Direito, destaca que fatores econômicos reforçam este tipo de violência, uma vez que: "Mais de $90 \%$ dos trabalhadores domésticos, mais vulneráveis economicamente na crise, são mulheres, e mais de $70 \%$ são negros, indicando a maior precariedade do emprego da mulher negra" (BIANQUINI, 2020).

A precariedade econômica, a incerteza política, a ansiedade em torno do vírus, o medo de ser contaminado (formas de prevenção e controle) e não ter estrutura hospitalar, a falta de lazer, a falta de socialização com outras pessoas, rotinas de casa, crianças em casa parecem reforçar, mas também estremecer a (des)ordem do gênero e suas intersecções. Para além disso, mas apresentando algumas raízes desse problema, tem-se a vulnerabilidade econômica, profissional, racial e étnica.

Patricia Hill Collins (2019) ressalta o jogo violento entre a visibilidade e invisibilidade da mulher negra: são corpos visíveis porque estão na ponta dos serviços domésticos, de limpeza, entre outros, mas tornam-se invisivelmente objetos, números e coisas, quando se fala em direitos, humanização, e isso ocorre por meio da despersonalização do racismo. Segundo a pesquisadora feminista negra, "as vidas das mulheres negras são uma série de negociações que almejam à reconciliação das contradições que separam nossas próprias imagens do eu, definidas internamente, como mulheres afroamericanas de nossa objetificação como o outro" (COLLINS, 2019, p. 274-275). É a visibilidade que torna esse corpo mais vulnerável, sua posição de outsider-incluído. Parece-nos que prevenir e combater este tipo de violência sejam funções inerentes ao Estado, ou seja, garantir que todas tenham direitos de existir em 
segurança, princípios constitucionais e democráticos, principalmente as mulheres, as crianças e as adolescentes negras, que são as mais violentadas.

As pesquisas destacam que o corpo mais vulnerável à violência doméstica é o da mulher negra, periférica, corpos sobrecarregados de trabalho porque, na sua grande maioria, são empregadas domésticas, faxineiras, cobradoras de transporte público, vendedoras e caixas. Não nos surpreende, portanto, que a primeira morte decorrente de COVID-19 no Brasil foi de uma mulher negra, funcionária doméstica, no Rio de Janeiro, que se contagiou através dos seus patrões que haviam voltado recentemente da ltália.

É impossível falar de violência doméstica sem pensar, principalmente, na relação raça, gênero e classe (Ângela DAVIS, 2017; COLLINS, 2019; Sueli CARNEIRO, 2019; Lélia GONZALES, 2019). Ao problematizar a violência contra mulheres e crianças negras, Audre Lorde (2019, p. 245) afirma que "normalmente se torna padrão dentro de nossas comunidades, um padrão pelo qual a masculinidade pode ser medida. Mas esses atos de ódio contra a mulher quase nunca são discutidos como crimes contra mulheres negras", ou seja, os atos violentos são cometidos não só por um 'patriarcado racista' (homens brancos), mas também por homens negros. Carneiro (2019) também ressalta que a experiência histórica de opressão contra mulheres negras não é reconhecida, assim como também não o é "a diferença qualitativa que o efeito da opressão sofrida teve e ainda tem na identidade feminina dessas mulheres" (CARNEIRO, 2019, p. 313).

A violência de gênero no âmbito privado e no doméstico se esbarra na violência estatal que, a par de dados estatísticos, entre outros, não implementa políticas públicas adequadas e exequíveis, justamente porque não se lança o olhar para os débitos estruturais contra a população negra. Há um reforço mútuo entre a violência de gênero privada e pública: "seu impacto é nos tornar duplamente sujeitas à violação - primeiro, nas mãos de parentes próximos e nas relações pessoais; segundo, nas mãos de agentes e promotores do capital" (ARRUZZA; BHATTACHARYA; FRASER, 2019, p. 60). Arruzza, Bhattacharya e Fraser (2019, p. 58) afirmam que "muitas vezes incitado pelo álcool, a vergonha e a ansiedade em relação à manutenção da dominação, esse tipo de violência de gênero é encontrado em todos os períodos do desenvolvimento capitalista", tornando-se virulento e difuso em épocas de crise.

\section{O cenário brasileiro: atores e relaçōes de força e poder}

É nesta conjuntura brasileira e mundial que o FBSP, em parceria com a empresa Decode Pulse, a pedido do Banco Mundial, lança a nota técnica Violência Doméstica durante a Pandemia de COVID-19 (FBSP, 2020). Em 16 de abril de 2020, o documento já problematiza o regime de isolamento que "tem imposto uma série de consequências não apenas para os sistemas de saúde, mas também para a vida de milhares de mulheres que já viviam em situação de violência doméstica" (FBSP, 2020, p. 03). Enfatiza que "sem lugar seguro, elas estão sendo obrigadas a permanecer mais tempo no próprio lar junto a seu agressor, muitas vezes em habitações precárias, com os filhos e vendo sua renda diminuída" (FBSP, 2020, p. 03).

A pandemia gera impactos em todos os níveis da nossa vida. É uma questão de saúde que atravessa todos os níveis da sociedade: social, cultural, político, jurídico, econômico e comunicativo, porque, na realidade, a pandemia de COVID-19 é um problema do capitalismo global, que escancara todos os danos causados por esse modo de produção de vida, e a violência contra as mulheres é um desses danos; um problema de saúde coletiva e pública que afeta diferentemente as feminilidades: das mulheres com deficiência, das comunidades rurais $e$ periféricas, quilombolas e indígenas, das mulheres negras e não negras, das mulheres em situação de rua, encarceradas, das mulheres trans, travestis, das mulheres em territórios criminalizados.

A nota técnica (FBSP, 2020) relata os dados alcançados pela variação nos níveis de violência doméstica nos primeiros dias das medidas de isolamento social. Para tanto, usa não só os dados oficiais coletados nas Secretarias Estaduais de Segurança Pública e/ou Defesa Social e Tribunais de Justiça sobre violência doméstica em seis estados (São Paulo, Pará, Acre, Rio Grande do Sul, Mato Grosso e Rio Grande do Norte), mas também dados captados pela rede social - Twitter - que relatam casos de brigas de casais e violência doméstica entre fevereiro e abril de 2020 .

Como já apontado aqui, a casa/residência é o local em que as mulheres (quando elas têm onde morar) estão mais sujeitas à violência. Neste contexto em que o isolamento faz com que as pessoas permaneçam em casa durante todo o dia, eram esperados o aumento de brigas, discussões e agressões muito em função das rotinas da casa, falta de trabalho, questões econômicas ou tão somente as práticas e ações do racismo, patriarcado e capitalismo, entre outros sistemas de opressão que atingem as mulheres.

A empresa Decode identificou "as formas pelas quais as histórias de violência são marcadas sob a perspectiva da percepção de terceiros. [...] e coletou um universo de pouco mais de 52 mil menções contendo algum indicativo de briga entre casais vizinhos realizadas entre fevereiro e abril" (FBSP, 2020, p. 11). Os dados mostram que "a maior parte dos relatos foi publicada às sextas-feiras, entre $20 \mathrm{~h}$ e $3 \mathrm{~h}$ da manhã, sendo que, aproximadamente $25 \%$ do 
total de relatos de brigas de casal foram feitos às sextas-feiras" (FBSP, 2020, p. 12). Outro dado importante é que as mulheres relataram mais do que os homens as brigas no Twitter, elas "foram as responsáveis por 67\% dos relatos identificados" (FBSP, 2020, p. 13). O estudo digital verificou que "houve um aumento em $431 \%$ de relatos de brigas de casal por vizinhos entre fevereiro e abril de 2020. [...] ainda que este crescimento não esteja sendo captado pelos registros oficiais de denúncias" (FBSP, 2020, p. 13).

Do estudo com os órgãos oficiais, o FBSP solicitou as seguintes variáveis:

1) $O$ quantitativo de registros de boletim de ocorrência produzidos pelas Polícias Civis de homicídio doloso de mulheres, feminicídios, estupros e estupros de vulnerável, ameaça a vítimas mulheres e lesão corporal dolosa decorrente de violência doméstica; 2) $O$ número de ocorrências atendidas pela Polícia Militar por meio do 190 em casos relativos à violência doméstica e sexual; e 3) O quantitativo de medidas protetivas de urgência (MPU) distribuídas e concedidas pelos Tribunais de Justiça. (FBSP, 2020, p. 04).

O estudo verifica que "o número de MPUs concedidas cai substancialmente em todos os territórios, assim como os registros de boletim de ocorrência que dependem da presença física das vítimas." (FBSP, 2020, p. 05). Quanto ao número de BO, "entre março de 2019 e março de 2020 , as denúncias de violência doméstica contra mulheres tiveram a seguinte variação: Ceará $(-29,1 \%)$; Acre $(-28,6 \%)$; Mato Grosso (-21,9\%); Rio Grande do Sul $(-9,4 \%)$; Rio Grande do Norte (+34\%)" (INSTITUTO PATRÍCIA GALVÃO, 2020). Essa redução não é uma surpresa, porque se as mulheres estão confinadas com seus agressores, como elas poderiam sair fisicamente para fazer o registro de ocorrências nas delegacias?

A Nota Técnica conclui que existem o aumento da violência doméstica e a dificuldade que as mulheres têm em acessar os equipamentos públicos presencialmente. E aponta "para a necessidade de inovar tanto nos mecanismos de denúncia, que podem ser feitos por terceiros, quanto no atendimento e orientação a estas mulheres" (FBSP, 2020, p. 14), como a ONU já ressaltava como uma das ações de enfrentamento. A partir deste estudo, das recomendações da OMS e da ONU, além de outras entidades civis e governamentais, o MMFDH e a sociedade civil, a partir de sites, blogs, páginas no Facebook e Instagram, movimentaram-se, e medidas e ações foram propostas. Dessa forma, segundo a Nota Técnica (FBSP, 2020, p. 14), alguns estados brasileiros: (i) lançaram aplicativo para que as vítimas denunciem a violência cometida de forma on-line; (ii) Nos Estados de São Paulo, Espírito Santo e Rio de Janeiro, a Secretaria de Segurança Pública disponibilizou o Boletim de Ocorrência eletrônico; (iii) O Tribunal de Justiça de São Paulo lançou o projeto Carta de Mulheres, em que as vítimas acessam o formulário on-line e uma equipe especializada (profissionais que trabalham na Coordenadoria da Mulher em Situação de Violência Doméstica e Familiar do Poder Judiciário) responderá com as orientações.

A Nota Técnica (FBSP, 2020, p. 15) destaca, ainda, outras iniciativas implementadas pela sociedade civil organizada: (i) O Mapa do Acolhimento lançou o \#TôComElas; (ii) os Institutos Justiça de Saia, Bem Querer Mulher e Nelson Willians Iançaram a força-tarefa Justiceiras, reunindo voluntárias para oferecer orientação jurídica e psicológica e assistência social gratuitas às vítimas de violência em todo o Brasil por WhatsApp e telefone. O Instituto Avon, organização privada, lançou \#IsoladasSimSozinhasNão e está produzindo conteúdos nas plataformas Papo de Homem e Quebrando o Tabu para auxiliar mulheres a identificar os sinais de relações abusivas.

As iniciativas mais pontuais e ágeis têm sido tomadas pelos estados; em São Paulo, Rio de Janeiro e Distrito Federal, as delegacias continuarão abertas $24 \mathrm{~h}$. No Rio de Janeiro e São Paulo, denúncias de violência doméstica não exigirão colhimento de provas imediatas, poderão ser feitas virtualmente. Em São Paulo foram criadas, no dia 31 de março, as Patrulhas Maria da Penha, que monitorarão mulheres vítimas de violência doméstica; o Tribunal neste estado também permitirá a concessão de medidas protetivas em caráter de urgência sem a apresentação de Boletim de Ocorrência por parte da vítima e a intimação dela por WhatsApp no caso de deferimento das medidas. No Distrito Federal, os acolhimentos feitos pelos Centros Especializados de Atendimento às Mulheres (CEAMs) vítimas de violência serão feitos por telefone, exceto em casos de urgência (BIANQUINI, 2020). No âmbito do poder legislativo, no dia 30 de março, foi apresentado o PL 1267/2020, de autoria de diversos deputados, que busca alterar a Lei 10714/2003 (Lei Maria da Penha) para ampliar a divulgação do Disque 180 enquanto durar a pandemia do COVID-19. O projeto propõe que toda informação exibida na rádio, na televisão e na internet que trate de episódios de violência contra a mulher deverá incluir menção expressa ao Disque 180. Além disso, alguns projetos irão autorizar o uso de recursos do Fundo Nacional de Segurança Pública em ações envolvendo prevenção e combate à violência doméstica.

Além dessas ações de enfrentamento, o estado de Minas Gerais, em 22 de maio de 2020, publica o Decreto de Lei Estadual 23.643, que dispõe sobre a comunicação a órgãos de segurança pública sobre ocorrências, ou indícios, de violência doméstica contra mulher, idosos, crianças, adolescentes nos condomínios residenciais durante o estado de calamidade decorrente da pandemia de COVID-19. Na próxima seção, serão apresentadas análises de 
discursos que circularam após a divulgação de dados coletados pelo FBSP, das informações e recomendações da ONU e da OMS e de algumas notícias midiáticas sobre a violência doméstica na pandemia de COVID-19. O objetivo é compreender como o governo/MMFDH reagiu e que tipo de ações foram empreendidas até o momento.

\section{Das relações de força e poder e as vozes discursivas 'autorizadas'}

Segundo Bianquini (2020), ainda que algumas ações foram tomadas, o governo federal ainda deixa muito a desejar, e muitas medidas estão sendo adotadas nos âmbitos estaduais, por meio das defensorias. São poucas as entrevistas, nas mídias televisiva e radiofônica, da Ministra Damares Alves ou de sua Secretária Nacional de Políticas para as Mulheres, Cristiane Britto, falando sobre tal problema. Há uma opção, clara, deste governo de usar como veículos de comunicação as redes sociais e suas ferramentas (lives, por exemplo), o que não alcança o grande público, principalmente as mulheres que sofrem as violências, uma vez que geralmente as informações são visualizadas pelos telefones móveis, e muitas pessoas não possuem acesso à internet até mesmo por questões financeiras. Além do fato de que os possíveis agressores têm acesso aos celulares.

O site do MMFDH apresenta, no final de março, a informação de que, pelos dados da Ouvidoria Nacional de Direitos Humanos (ONDH), "a média diária entre os dias 1 e 16 de março foi de 3.045 ligações recebidas e 829 denúncias registradas, contra 3.303 ligações recebidas e 978 denúncias registradas entre 17 e 25 deste mês" (MMFDH, 2020a). Informa ainda que o Disque 100 e o Ligue 180 funcionarão 24 horas por dia, todos os dias, inclusive aos finais de semanas e aos feriados, sendo acionados de qualquer lugar do Brasil e de vários países do exterior.

Em 26 de março, o MMFDH emite o Ofício-Circular 1/2020/DEV/SNPM/MMFDH, cujo assunto é: "Recomendações em relação às ações de enfrentamento à violência contra meninas e mulheres no contexto da pandemia de COVID-19" (BRASIL, 2020, p. 01). Nesse documento, considerando o aumento no número de ligações na Central de Atendimento à Mulher - Ligue 180, o documento da ONU Mulheres Gênero e COVID-19 na América Latina e no Caribe: dimensões de gênero na resposta, de março de 2020, que traz recomendações para o enfrentamento à violência de gênero frente à pandemia da COVID-19, e as Recomendações do Comitê de Peritas do Mecanismo de Acompanhamento da Convenção de Belém do Pará, a Secretaria recomenda várias ações que podem ser visualizadas em BRASIL (2020, p. 02).

Das recomendações, destacamos aqui para uma reflexão discursivo-crítica duas ações: (i) Campanha de sensibilização para vizinhos e comunidade em geral quanto à importância de se denunciar a violência doméstica e familiar contra as mulheres, (ii) Programa Famílias Fortes'. Para as titulares do MMFDH e da Secretaria Nacional da Família (SNF), "o momento é de rever as relações familiares e de trabalho, fortalecer vínculos e promover a harmonia dentro dos lares" (MMFDH, 2020b). Para a Ministra Damares, "são formas de combater a violência e diminuir os conflitos familiares, que vemos aumentar tanto na pandemia" (MMFDH, 2020b). Para a Secretária e a Ministra, basta que as pessoas aprendam "a conviver e a crescer nas virtudes da convivência, que é a paciência, a compreensão, saber ouvir, parar para prestar atenção ao outro" (MMFDH, 2020b).

Para um governo notadamente baseado em valores ultraconservadores da extremadireita, o conceito de família, inevitavelmente, assume muitas particularidades que não atendem à sua natureza ambivalente e plural. Segundo Bruna Soares Aguiar e Matheus Ribeiro Pereira (2019), o atual governo se encaixa na Maré Azul, movimento que se caracteriza "em torno de um posicionamento moralista e conservador a respeito da posição da mulher na sociedade" (AGUIAR; PEREIRA, 2019, p. 11) e tem "ligação fundamentada em princípios religiosos, principalmente no que tange ao conceito de família e o papel da mulher como cuidadora" (AGUIAR; PEREIRA, 2019 , p. 11). É notório o alinhamento discursivo da Ministra Damares e de sua Secretária com os discursos da nova direita antifeminista e de forte influência religiosa. Susan Faludi (2001), problematizando tais questões no contexto americano, afirma que a Maré Azul produz uma narrativa antifeminista em que responsabiliza o feminismo pelo 'desmantelo' da família. Ao fazer isso, Damares nega os estudos científicos sobre gênero e as conquistas dos direitos das mulheres e produz um discurso de gestão da precariedade bastante violento para quem já é vulnerável.

Damares reforça sempre, em seus discursos, que faz parte de um governo pró-vida e prófamília, reproduzindo o que Faludi (2001) denomina de narrativa da Nova Direita:

rotula sua resistência aos recém adquiridos direitos de reprodução das mulheres como 'luta pela vida'; sua posição à recém-conquistada liberdade sexual das mulheres passou a ser chamada de 'pró-castidade'; e sua hostilidade à entrada em massa das mulheres no mercado de trabalho tornou-se 'pró-maternidade'. (FALUDI, 2001, p. 245-246).

1 O Programa Famílias Fortes (PFF-BR 10-14) é uma adaptação à realidade brasileira do Strengthening Families Programme (SFP-UK), elaborado no Reino Unido pela Oxford Brookes University. 
Sabemos que família, como qualquer instituição, se constrói a partir de normas, valores, processos sociais, históricos e culturais atravessados por relações de poder; são muitas as formas de organização familiar, seus afetos, interações, parentabilidade e coabitação (BIROLI, 2018): são famílias indígenas, quilombolas, negras, homoafetivas, heterossexuais, monoparentais, biparentais, entre outras.

Dessa forma, não é possível que todas as famílias tenham o mesmo tipo de convivência pacífica nem considerar que apenas desenvolver a paciência ou a escuta diminuiria a violência, há outras intersecções que impedem tal romantização virtuosa e cristã, materializada discursivamente nos léxicos usados pela Secretária da Família: virtudes da convivência, compreensão, saber ouvir, prestar atenção no outro. Não basta ser apenas virtuoso para que a violência não aconteça.

Como um programa que tem como objetivo estabelecer limites e regras para uma boa convivência pacífica e afetuosa pode na prática dar certo dentro desse contexto? Além disso, o Programa Famílias Fortes tem como foco fortalecer vínculos familiares entre pais e filhos (de 10 a 14 anos), de forma a "criar condições favoráveis para o bom desenvolvimento dos filhos, e tende a afastá-los de condutas de risco" (MMFDH, 2020b). Ou seja: o projeto é voltado para adolescentes e a prevenção e redução de uso de álcool e outras drogas.

Desconsiderando o quanto grave é a situação das mulheres vítimas de violência doméstica, conforme apontam todos os estudos já apresentados neste artigo, o MMFDH (2020b) emitiu, em seu site, a seguinte orientação:

Como forma de 'estimular' a população 'a melhorar a qualidade' das relações entre os membros da família, aproveitando o contexto de afastamento, a SNF 'disponibiliza', desde o último dia 13, uma série de vídeos do Programa Famílias Fortes (PFF). A ferramenta 'ensina pais e filhos a desenvolverem maneiras eficazes de comunicação e relacionamento, mostra aos pais a importância de apoiar os filhos', ensiná-los a lidar com o estresse e a pressão dos amigos, além de promover uma expectativa de futuro aos jovens. (MMFDH, 2020b, grifos nossos).

Como um programa que tem um objetivo, muito claro, de ensinar "pais e filhos a desenvolverem maneiras eficazes de comunicação e relacionamento, mostra aos pais a importância de apoiar os filhos, ensiná-los a lidar com o estresse e a pressão dos amigos" (MMFDH, 2020b), poderá, no contexto de isolamento e distanciamento sociais, apenas por meio de vídeos, minimizar, controlar ou acabar com a violência? São vários os fatores que atravessam aqui a eficiência desta ação: (i) todos têm acesso à internet para visualizar esses vídeos?; (ii) como eles terão acesso a esta informação se não for por uma ação virtual?; (iii) se já há um quadro de violência física instaurado, de que forma a família se reuniria para assistir a algo que está voltado para os filhos e não especificamente para a violência doméstica? A ação proposta é completamente inadequada e irreal, mostra que o acesso aos dados e informações dos vários órgãos governamentais é usado para outros controles e privilégios sociodiscursivos e políticos e para a visível negação do problema, principalmente a pauta do gênero. Ronaldo de Almeida (2019), discutindo sobre conservadorismo, evangelismo, bolsonarismo e crise brasileira, afirma que: "De um lado, um movimento de manutenção da tradição cristã fortemente marcada pelo catolicismo, de outro, um movimento mais proativo e transformador dos comportamentos feito pelo evangelismo." (ALMEIDA, 2019, p. 208).

À luz da conjuntura sociopolítica mundial e da brasileira, em que meninos vestem azul e meninas, rosa, a campanha de conscientização e enfrentamento à violência doméstica voltada para o período da pandemia do COVID-19 é lançada, pelo governo, oficialmente, no dia 15 de maio de 2020, no Dia Internacional da Família, cujo slogan é: Denuncie a violência doméstica - para algumas famílias, o isolamento está sendo ainda mais difícil.

O conceito de família assume uma centralidade discursivo-ideológica de cunho conservador e de extrema-direita, conforme podemos observar no discurso da Secretária da Família (MMFDH, 2020b): "O cerne da relação humana é a família. Se a gente conseguir fortalecer, rever relacionamentos, todo o desequilíbrio vai ser prevenido e, depois, mais bem acompanhado.". Damares continua afirmando que "a pessoa que teve uma família, foi amada, foi educada, ela vai ser um verdadeiro cidadão, pois a família é o berço da cidadania e da saúde." (MMFDH, 2020b). É, portanto, "fundamental para o desenvolvimento econômico e social" (MMFDH, 2020b).

A orientação ideológica do governo desconsidera o viés jurídico moderno do conceito de família, que torna o princípio da dignidade da pessoa humana (art. $1^{\circ}$, III) o principal marco de mudança do paradigma da família, ou seja, "o único requisito para a sua constituição não é mais jurídico e sim fático: o afeto", conforme ressalta Leonardo Alves (2006, p. 330), em O reconhecimento legal do conceito moderno de família - o art. $5^{\circ}$, ii e parágrafo único, da lei no 11.340/2006 (Lei Maria da Penha). Esse princípio da dignidade da pessoa humana orienta que "o ordenamento jurídico deverá sempre reconhecer como família todo e qualquer grupo no qual os seus membros enxergam uns aos outros como seu familiar" (ALVES, 2006, p. 330). No discurso 
de lançamento da campanha, a Ministra reforça isso ao dizer que a família é o centro das ações do seu ministério e do governo e enfatiza que a campanha não está tratando especificamente da violência conjugal, mas da doméstica, abrangendo crianças, adolescentes, idosos, pessoas com deficiência:

'A maioria da violência contra as crianças a gente descobre na escola ou na creche. Essas crianças não estão na creche e não estão na escola. A criança não liga, não fala, não vai denunciar, não usa aplicativo. Estamos apavorados com o que vamos descobrir pós-pandemia', disse a ministra, apelando para que vizinhos e parentes fiquem atentos aos sinais de violência. [...] 'O objetivo é despertar a urgência em exercitar o dever cívico de informar às autoridades sobre as situações de violência dentro dos lares' [...] (Juliana Domingos de LIMA, 2020).

Segundo a Ministra Damares Alves, a "violência doméstica não tem gênero" (LIMA, 2020), e, ao falar isso, apresenta as peças da campanha trazendo como possíveis vítimas: um adolescente, uma menina com síndrome de Down, um idoso e uma mulher.

A negação de uma perspectiva interseccional de gênero na campanha vem na esteira da retórica de negação do uso, estrategicamente equivocado, do próprio conceito de gênero, aplicado com alto investimento ideológico numa narrativa de destruição da família, principalmente das crianças, como bem chama atenção Jimena Furlani (2016, p. 04):

Não faz nenhum sentido dizer que os estudos de gênero negam a biologia; os estudos de gênero discordam é do determinismo biológico - quando a biologia é utilizada pra definir nosso destino social. Tenho que admitir que a construção dessa estratégia foi muito inteligente! Destaca-se o brilhantismo em construir uma narrativa, suficientemente ameaçadora para sociedade, na medida em que ela se volta para a criança e a família no seu intuito destruidor. Não há nada que mobilize mais as pessoas, principalmente pais e mães, do que alardear que 'algo' ameaça suas crianças e que há um complô mundial para destruir sua família.

Em seu discurso, promove o entrecruzamento do ordenamento religioso a um ordenamento moral-cívico, minimizando alarmantemente um grave problema estrutural sociopolítico que é a violência doméstica. Ao fazer isso, nega a violência $L G B T Q$, nega a violência nos territórios, nega a violência no corpo atravessado por vários eixos de opressão e vulnerabilidades. Alinhamo-nos à Jurema Werneck e Nilza Iraci (2016, p. 05), ao afirmarem que "a violência é um fenômeno complexo e, nas sociedades afetadas pelo racismo patriarcal heteronormativo, atinge de maneira desproporcional às populações de pele escura, com forte marca do sexismo e das fobias LGBT.".

Lima (2020), em 19 de maio de 2020, no jornal Nexo, relata em seu texto algumas críticas feitas por Beatriz Accioly Lins sobre a referida campanha. Lins é integrante da equipe do Justiceiras, que prestou assistência a mais de 500 mulheres desde o fim de março, por meio do WhatsApp, e, ao analisar a campanha, expõe a sua crítica a partir de três eixos: (i) Denúncia de vizinhos, já era uma ação existente; (ii) Família - o conceito de família nuclear patriarcal; (iii) Negação do viés do gênero.

Werneck e Iraci organizaram em 2016 um Dossiê sobre a Violação dos Direitos das Mulheres Negras Brasileiras, resultado de um trabalho conjunto do Instituto da Mulher Negra e Criola (Geledés) - Organização de Mulheres Negras -, no qual os estudos apresentam diferentes formas de violações de direitos humanos de mulheres negras brasileiras. Nesse dossiê, as pesquisadoras negras chamam atenção para o fato de que as leis Maria da Penha e Feminicídio "negligenciam as iniquidades provocadas pelo racismo e a complexidade da violência enfrentada pelas mulheres negras." (WERNECK; IRACI, 2016, p. 14). Sobre a violência de gênero e a Lei Maria da Penha, denunciam que, desde a sua vigência, esta lei "não foi capaz de reduzir a vitimização das mulheres negras de forma direta. No entanto, esta Lei permitiu a desaceleração do crescimento dos assassinatos das mulheres negras" (WERNECK; IRACI, 2016, p. 32), como bem pudemos observar nos dados do Atlas da violência (IPEA, FBPS, 2019) apresentados neste texto.

As pesquisadoras denunciam ainda que:

Muitas mulheres negras assassinadas eram defensoras de direitos humanos. A responsabilização do Estado brasileiro nestas mortes se dá por duas vias principais: negligência ou ineficiência de políticas públicas para a garantia de direitos, como por exemplo, de titulação de terras quilombolas, não proteção de territórios e vidas das comunidades, entre outras; e pela ação direta de seus agentes: nestes casos, as polícias têm papel preponderante. (WERNECK; IRACI, 2016, p. 14).

Além disso, ressaltam que "o Estado brasileiro negligencia a coleta e divulgação de informações acerca da população LGBT, especialmente em relação a lésbicas, travestis e transexuais negras." (WERNECK; IRACI, 2016, p. 23), registrando que, em 2012, "6\% das vítimas de estupro que apresentaram denúncias ao Disque 100 eram lésbicas, e contribuíram para dar visibilidade ao fenômeno conhecido como estupro corretivo." (WERNECK; IRACl, 2016, p. 25).

Como pudemos observar, a violência contra as mulheres é constituída por vários campos: econômico, político e cultural e atravessada pelas ações e práticas do racismo e do 
cisheteropatriarcalismo, autoritarismo e controle. Para o Centro Feminista de Estudos e Assessoria (CFEMEA) (2020), a violência contra a mulher é base do patriarcado, mas se "relaciona diretamente com os outros sistemas de opressão - capitalismo e racismo - e outras formas de violência, como LGBTfobia, o capacitismo, entre outras." (CFEMEA, 2020). A violência não acontece da mesma forma em todas as mulheres, e, por este motivo, "que seu enfrentamento não pode ser pensado a partir de um único parâmetro" (CFEMEA, 2020), como a Ministra Damares propõe em sua campanha, ao negar completamente o viés interseccional do gênero. Além de negar que a violência contra as mulheres é estrutural, ainda não consegue compreender a complexidade que recai sobre esse corpo e, ao fazer isso, camufla essa violência, a invisibiliza de forma que "não aparece como uma ruptura da normalidade. Em particular, a violência estrutural tem beneficiários, mas não tem necessariamente perpetradores particularizáveis" (CFEMEA, 2020).

O enfrentamento a essa violência precisa estar atento a esta diversidade corpórea porque, como bem alerta CFEMEA (2020), é preciso um "acolhimento com escuta para essas mulheres se encorajarem a sair dessa situação; afinal, ceder às várias formas de violência não significa aceitar". Até o fechamento deste texto, dia 12 de junho de 2020, a campanha do governo contra a violência doméstica, com todas as suas problematizações como tentamos apresentar aqui, ainda não estava circulando nos canais televisivos abertos no Brasil, a quem a grande maioria da população tem acesso.

\section{Explanatória crítica: identificando possiveis caminhos e ações}

Como pode uma análise de conjuntura como esta contribuir para a resolução de problemas tais como o que apresentamos? Acreditamos que conectar as conjunturas políticas, sociais e acadêmicas no que tange à violência doméstica no contexto de pandemia de COVID-19 permite-nos compreender que tal problemática está inserida numa rede de práticas sociais mais complexa. Dessa forma, dialogar tais conjunturas com as respostas dadas pelo governo brasileiro e o MMFDH permite-nos observar o forte viés ideológico do discurso desses atores calcado, principalmente, pela negação não só dos dados estatísticos produzidos por institutos de pesquisa, mas das múltiplas constituições familiares quanto do viés do gênero e de suas colisões com outros eixos identitários. Tal negação incide sobre a dificuldade em realizar ações eficazes de enfretamento e de políticas públicas eficazes e da própria compreensão do problema como uma violação dos direitos humanos.

No entanto, movimentos de mulheres vêm atuando de forma consciente no combate à violência contra as mulheres no contexto da pandemia de COVID-19. Algumas ações têm sido desenvolvidas: capacitação profissional de mulheres a fim de dar a elas estabilidade financeira, como no caso das intervenções feitas na comunidade de Paraisópolis em São Paulo; construção de campanhas voltadas a melhorias de qualidade de vida, como Mulheres sem Terra contra os vírus e as violências, que, todo dia 08 do mês, arrecada máscaras, faz plantios de árvores, bem como se reúne em assembleias. Além disso, algumas empresas têm elaborado ações, como Magazine Luiza.

Ações de coletivos que centralizam suas intervenções em uma perspectiva interseccional também têm atuado fortemente neste contexto: como o Mães de Pachanamá, na Paraíba, que promove campanhas para arrecadação e para distribuição de cestas básicas, produtos de higiene e enxovais para mães; o Abayomi - Coletiva de mulheres negras, também da Paraíba, que oferece cursos para a articulação de mulheres líderes comunitárias. No sudeste, o coletivo Mulher eu sou, grupo de capoeiristas de Belo Horizonte, produz remédios naturais visando à saúde da mulher, enquanto no Rio de Janeiro, o coletivo Mulheres na Ciência tem realizado campanhas no intuito da garantia da segurança alimentar e financeira de mulheres.

Podemos dizer que essas ações podem ajudar na superação do problema sociossemiótico em tela porque nos mostram tanto a articulação de movimentos sociais e feministas para o combate à violência contra as mulheres quanto a vulnerabilidade das políticas públicas federais e estaduais em tempos de pandemia. É necessário discutir e fazer circular tais ações, assim como cobrar uma atuação mais consciente do Estado, que leve em consideração a pluralidade das constituições familiares e a importância da discussão de gênero e suas interseccionalidades para a promoção de políticas públicas.

\section{Referências}

AGUIAR, Bruna Soares; PEREIRA, Matheus Ribeiro. "O antifeminismo como backlash nos discursos do governo Bolsonaro". Agenda Política - Revista de Discentes de Ciência Política da Universidade Federal de São Carlos [on-line]. São Carlos, 2019, v. 7, n. 7, p. 08-35. Disponível em http://www. agendapolitica.ufscar.br/index.php/agendapolitica/article/view/271. ISSN 2318-8499. Acesso em 03/06/2020. 
ALMEIDA, Ronaldo de. "Bolsonaro presidente: conservadorismo, evangelismo e a crise brasileira". Novos estudos. CEBRAP [on-line]. São Paulo, 2019, v. 38, n. 1, p. 185-213. Disponível em http:/l novosestudos.uol.com.br/wp-content/uploads/2019/06/11_almeida_113_p184a213.pdf. E-ISSN 19805403. Acesso em 25/05/2020.

ALVES, Leonardo. "O reconhecimento legal do conceito moderno de família o art. $5^{\circ}$, II e parágrafo único, da Lei no 11.340/2006 (Lei Maria da Penha)". Revista Jus Navigandi [on-line], Teresina, 2006, ano 11, n. 1225. Disponível em https://jus.com.br/artigos/9138. ISSN 1518-4862. Acesso em $03 / 06 / 2020$

ARRUZZA, Cinzia; BHATTACHARYA, Tithi; FRASER, Nancy. Feminismo para os 99\%: um manifesto. São Paulo: Boitempo, 2019.

BIANQUINI, Heloisa. "Combate à violência doméstica em tempos de pandemia: o papel do Direito". Revista Consultor Jurídico [on-line]. 2020. Disponível em https://www.conjur.com.br/2020-abr-24/ direito-pos-graduacao-combate-violencia-domestica-tempos-pandemia. Acesso em 24/04/2020.

BIROLI, Flávia. Gênero e desigualdades: Limites da democracia no Brasil. São Paulo: Boitempo, 2018.

BOND, Letícia. "Violência contra mulher aumenta 44,9\% durante pandemia". Agência Brasil [online], 2020. Disponível em https://agenciabrasil.ebc.com.br/direitos-humanos/noticia/2020-04/spviolencia-contra-mulher-aumenta-449-durante-pandemia. Acesso em 20/04/2020.

BRASIL. Ministério da Mulher, da Família e dos Direitos Humanos. Ofício circular 001/2020/DEV/ SNPM/MMFDH. Brasília: Ministério da Mulher, da Família e dos Direitos Humanos, 26 mar. 2020. Disponível em https://sittel.pc.sc.gov.br/arquivos/SEI MDH1 1361 14.pdf.pdf. Acesso em 03/06/2020.

CARNEIRO, Sueli. "Enegrecer o feminismo: a situação da mulher negra na América Latina a partir da perspectiva de gênero". In: HOLLANDA, Heloisa de Buarque (Org.). Pensamento Feminista: conceitos fundamentais. Rio de Janeiro: Bazar do Tempo, 2019. p. 313-322.

CENTRO FEMINISTA DE ESTUDOS E ASSESSORIA (CFEMEA). "Violência doméstica e os precipícios do machismo". Outras Palavras [on-line]. 18 abr. 2020. Disponível em https://outraspalavras.net/ feminismos/violencia-domestica-nossa-fragil-e-machista-democracial. Acesso em 25/05/2020.

CHOULIARAKI, Lilie; FAIRCLOUGH, Norman. Discourse in late modernity: Rethink critical discourse analyses. London: Routledge, 1999.

COLLINS, Patricia Hill. "Pensamento feminista negro: o poder de autodefinição". In: HOLLANDA, Heloisa de Buarque (Org.). Pensamento Feminista: conceitos fundamentais. Rio de Janeiro: Bazar do Tempo, 2019. p. 271-312.

CRENSHAW, Kimberlé W. "A intersecionalidade na discriminação de raça e gênero". In: WV. AA. Cruzamento: raça e gênero. Brasília: Unifem, 2004. p. 07-16.

DAVIS, Ângela. Mulheres, cultura e política. São Paulo: Boitempo, 2017.

FALUDI, Susan. Backlash: o contra-ataque na guerra não declarada contra as mulheres. Rio de Janeiro: Rocco, 2001.

FAIRCLOUGH, Norman; MELO, Iran Ferreira de. "Análise Crítica do Discurso como método em pesquisa social científica". Linha D’Água. 2012, v. 25, n. 2, p. 307-329. Disponível em https://www. revistas.usp.br/linhadagua/article/view/47728. Acesso em 02/12/2020.

FÓRUM BRASILEIRO DE SEGURANÇA PÚBICA (FBSP). Violência Doméstica durante a Pandemia de COVID-19. 2020. Disponível em http://forumseguranca.org.br/wp-content/uploads/2018/05/ violencia-domestica-covid-19-v3.pdf. Acesso em 29/04/2020.

FÓRUM BRASILEIRO DE SEGURANÇA PÚBLICA (FBSP); INSTITUTO DATAFOLHA (DATAFOLHA). VisíveI e invisível: a vitimização de mulheres no Brasil. 2. ed. 2019. Disponível em http://www. forumseguranca.org.br/wp-content/uploads/2019/02/Infogra\%CC\%81 fico-vis\%C3\%ADvel-einvis\%C3\%ADvel-2.pdf. Acesso em 20/04/2020.

FURLANI, Jimena. "Existe 'Ideologia de gênero’?”. Pública [on-line]. Disponível em: https://apublica. org/2016/08/existe-ideologia-de-genero/. 2016. Acesso em 25/05/2020. 
GOMES, Maria Carmen Aires; VIEIRA, Viviane. "Estudos Discursivos Críticos: análise crítica de problemas sociais discursivamente manifestos". In: EMEDIATO, Wander; MACHADO, Ida Lucia; LARA, Glaucia Muniz Proença (Org.). Teorias Discursivas: novas práticas e formas discursivas. Campinas: Pontes Editora, 2020. p. 173-200.

GONZALES, Lélia. "A categoria político-cultural da Amefricanidade". In: HOLLANDA, Heloisa de Buarque (Orgs.). Pensamento Feminista: conceitos fundamentais. Rio de Janeiro: Bazar do Tempo, 2019. p. 341-356.

INSTITUTO DE PESQUISA ECONÔMICA APLICADA (IPEA); FÓRUM BRASILEIRO DE SEGURANÇA PÚBLICA (FBSP). Atlas da Violência 2019. Brasília, Rio de Janeiro, São Paulo: IPEA; FBSP, 2019. Disponível em http://www. ipea.gov.br/portal/images/stories/PDFs/relatorio institucional/190605_atlas_da_violencia_2019.pdf. Acesso em 20/05/2020.

INSTITUTO DE PESQUISA ECONÔMICA APLICADA (IPEA); INSTITUTO DATAFOLHA (DATAFOLHA). Visível e Invisível: vitimização de mulheres no Brasil. 2019. Disponível em https://www12.senado.leg.br/ institucional/procuradoria/proc-publicacoes/Incografico\%20-vitimizacao-de-mulheres-no-brasil2deg-edicao-. Acesso em 02/06/2020.

INSTITUTO PATRÍCIA GALVÃO. Relatos de briga de casais aumentam 431\% desde o início do isolamento provocado pelo coronavírus, diz estudo. 20 abr. 2020. Disponível em https:/l agenciapatriciagalvao.org. br/violencia/violencia-domestica/relatos-de-briga-de-casaisaumentam-431-desde-o-inicio-do-isolamento-provocado-pelo-coronavirus-diz-estudo/. Acesso em 20/04/2020.

LIMA, Juliana Domingos de. "A campanha oficial contra a violência doméstica. E as críticas a ela". Nexo Jornal. 19 maio 2020. Disponível em https://www.nexojornal.com.br/expresso/2020/05/19/Acampanha-oficial-contra-a-viol\%C3\%AAncia-dom\%C3\%A9stica.-E-as-cr\%C3\%ADticas-a-ela. Acesso em 02/06/2020.

LORDE, Audre. "Idade, raça, classe e gênero: mulheres redefinindo a diferença". In: HOLLANDA, Heloisa de Buarque (Org.). Pensamento Feminista: conceitos fundamentais. Rio de Janeiro: Bazar do Tempo, 2019. p. 239-250.

MINISTÉRIO DA MULHER, DA FAMÍLIA E DOS DIREITOS HUMANOS (MMFDH). Coronavírus: sobe o número de ligações para canal de denúncia de violência doméstica na quarentena. 2020a. Disponível em https://www.gov.br/mdh/pt-br/assuntos/noticias/2020-2/marco/coronavirus-sobe-onumero-de-ligacoes-para-canal-de-denuncia-de-violencia-domestica-na-quarentena. Acesso em 24/04/2020.

MINISTÉRIO DA MULHER, DA FAMÍLIA E DOS DIREITOS HUMANOS (MMFDH). Estímulo a relações familiares saudáveis é alvo da SNF na pandemia. 2020b. Disponível em https://www.gov.br/mdh/ pt-br/assuntos/noticias/2020-2/abril/estimulo-a-relacoes-familiares-saudaveis-e-alvo-da-snf-napandemia. Acesso em 20/04/2020.

MLAMBO-NGCUKA, Phumzile. "Violência contra mulheres e meninas é pandemia das sombras". Nações Unidas ONU, 08 abr. 2020. Disponível em https://nacoesunidas.org/artigo-violenciacontra-mulheres-e-meninas-e-pandemia-das-sombras/. Acesso em 20/04/2020.

ORGANIZAÇÃO DAS NAÇÕES UNIDAS (ONU). "Chefe da ONU alerta para aumento da violência doméstica em meio à pandemia do coronavírus". Nações Unidas Brasil. 2020. Disponível em https://nacoesunidas.org/chefe-da-onu-alerta-para-aumento-da-violencia-domestica-em-meioa-pandemia-do-coronavirus/. Acesso em 08/04/2020.

SANTOS, Maria Cecília MacDowell dos. "Para uma abordagem interseccional da Lei Maria da Penha". In: MACHADO, Isadora Vier (Org.). Uma década de lei Maria da Penha: percursos, práticas e desafios. Curitiba: CRV, 2017. p. 39-61.

SOUZA, Betinho Herbert José de. Como se faz Análise de Conjuntura. 34. ed. Petrópolis, RJ: Vozes, 1997.

VIEIRA, Pâmela Rocha; GARCIA, Leila Posenato; MACIEL, Ethel Leonor Noia. "Isolamento social e o aumento da violência doméstica: o que isso nos revela?". Rev. bras. epidemiol [on-line]. Rio de Janeiro, 2020, v. 23, p. 01-05. Disponível em http://www.scielo.br/scielo.php?script=sci arttext\&pid =S1415-790X2020000100201\&lng=en\&nrm=iso. DOI: 10.1590/1980-549720200033. Acesso em 06/05/2020. 
WERNECK, Jurema; IRACI, Nilza. A situação dos direitos humanos das mulheres negras no Brasil: violências e violações. São Paulo: Criola-Geledés, 2016.

Maria Carmen Aires Gomes (mcgomes@ufv.br) é professora associada do Departamento de Letras da UFV/MG, onde atua no POSLET, na área de Estudos do Texto e Discurso. É professora colaboradora no Poslin-UFMG. PhD em Estudos da Linguagem, pela PUCSP (2010), e em Linguística, pela UnB (2016). Coordena o Grupo de Pesquisa Afecto/UFV/Nieg. Sua pesquisa volta-se para questões sobre corpos, gêneros e discursos por meio de narrativas midiáticas e de vida.

Alexandra Bittencourt de Carvalho (alexandraportuguês@yahoo.com.br) é doutoranda em Estudos do Texto e Discurso do Programa de Pós-Graduação em Linguística da Universidade Federal de Minas Gerais. Mestra em Estudos Discursivos pela Universidade Federal de Viçosa, professora de Linguagens no ensino médio e pré-vestibular e integrante do Afecto Abordagens faircloughianas para estudos sobre corpo/discurso textualmente orientados.

\section{COMO CITAR ESTE ARTICO DE ACORDO COM AS NORMAS DA REVISTA}

GOMES, Maria Carmen Aires; CARVALHO, Alexandra Bittencourt de. "Pandemia de COVID-19 e violência doméstica na conjuntura sociopolítica brasileira". Revista Estudos Feministas, Florianópolis, v. 29, n. 3, e74781, 2021.

\section{CONTRIBUIÇĀO DE AUTORIA}

Maria Carmen Aires Gomes: concepção/desenho da pesquisa, coleta de dados e análise de dados, discussão de resultados e redação.

Alexandra Bittencourt de Carvalho: análise de dados, discussão de resultados e redação.

\section{FINANCIAMENTO}

Não se aplica.

\section{CONSENTIMENTO DE USO DE IMAGEM}

Não se aplica.

\section{APROVAÇĀO DE COMITÊ DE ÉTICA EM PESQUISA}

Não se aplica.

\section{CONFLITO DE INTERESSES}

Não se aplica.

\section{LICENÇA DE USO}

Este artigo está licenciado sob a Licença Creative Commons CC-BY 4.0 International. Com essa licença você pode compartilhar, adaptar, criar para qualquer fim, desde que atribua a autoria da obra.

\section{HISTÓRICO}

Recebida em 15/06/2020

Reapresentado em 08/02/2021

Aceita em 10/02/2021 